\title{
OS MÉTODOS APLICADOS NOS ENCONTROS PRESENCIAIS DOS CURSOS TÉCNICOS A DISTÂNCIA DO SENAI-GO
}

\author{
GOIÂNIA/GO AGOSTO/2018 \\ Janaína Christina Araújo de Souza Ribeiro - SENAI - janainasouza.sesi@sistemafieg.org.br \\ Tipo: Relato de Experiência Inovadora (EI) \\ Categoria: Métodos e Tecnologias \\ Setor Educacional: EDUCAÇÃO MÉDIA E TECNOLÓGICA
}

\begin{abstract}
RESUMO
A evolução das tecnologias digitais produz novos sentidos na perspectiva educacional, pois exige $o$ desenvolvimento de uma série de competências por meio de métodos de ensino que favoreçam o processo de aprendizagem. Alinhada a essa expectação o presente trabalho apresenta o relato dos métodos aplicados nos encontros presenciais dos cursos técnicos a distância do Senai-GO. Além do desenvolvimento de capacidades técnicas essenciais à atuação profissional promove a autonomia, criatividade e iniciativa, sendo que os processos de ensino e aprendizagem se comunicam e se correlacionam.
\end{abstract}

Palavras-chave: competências; métodos; processos; aprendizagem. 


\section{Introdução}

Apesar de consolidado, a Educação a Distância - EaD ainda sofre de desconfiança dos alunos que, reconhecidamente, têm sua cultura de aprendizagem no sistema presencial. Porém, a fim de minimizar essa insegurança e, talvez, algum desconforto causado aos alunos, deve-se tê-lo como foco, definindo o papel de diálogo e pedagógico do tutor. $\mathrm{A}$ interatividade propõe aos alunos uma nova maneira de aprendizado, atuando como facilitador, dando a autonomia que muitas vezes não têm no sistema presencial.

Há de se ter em mente uma nova filosofia em EaD despertando no aluno sua capacidade de construir seu próprio conhecimento para não continuar uma aprendizagem mecânica e repetitiva. O positivismo do tutor e a humildade em acolher contribuições por parte do educando no conteúdo apresentado, funcionam como elemento agregador no processo. Por isso, a velha prática do ensino unidirecional, eu ensino e você aprende, deve ser abandonada, no intuito de se buscar uma ação comum com aquele pelo qual se trabalha, o aluno.

O docente deve esquecer a prática do ensino compulsório, autoritário, para que não seja taxado de simples repassador de conteúdo. Ao mesmo tempo, deve ele desenvolver o papel de "saber", "saber fazer" e, também, "querer". O "saber" é, ou deve ser inerente à posição que ocupa o tutor. O "saber fazer" é a habilidade, e não menos importante atuando com flexibilidade em todo o processo. Já o querer, parte do pressuposto de que precisasse repassar ao aluno a importância da autoaprendizagem.

A promoção da autonomia do sujeito, suas humanização e transformação, gerindo e construindo o próprio aprendizado, contribuirá em uma maior autonomia política, econômica e social para o exercício da cidadania. É fundamental, em todas as esferas do aprendizado, preparar o sujeito em seus saberes e aptidões, capacitando-o para o entendimento da complexidade das relações profissionais, observando a diversidade, agindo com flexibilidade, incutindo nele uma consciência de si próprio e do papel a desempenhar enquanto cidadão. O tutor precisa acreditar no aluno, precisa incentivá-lo a desenvolver conhecimentos dentro e fora dos limites do ambiente de aprendizagem (SIMÕES, 2010).

O objetivo deste trabalho é descrever a metodologia aplicada nos encontros presenciais dos cursos técnicos do Senai Goiás como forma de trabalhar e exercitar a prática da teoria apreendida no ambiente virtual de aprendizagem.

\section{Fundamentação Teórica}


A evolução social e tecnológica vem causando impactos significativos na vida das pessoas, essas inovações tecnológicas têm rompido fronteiras e aproximado virtualmente as pessoas por maior que seja a distância física entre elas. A tecnologia facilita processos, acelera as comunicações e promove a democratização e a acessibilidade do ensino por meio da Educação a Distância. O crescimento da oferta de cursos e número de usuários evidencia muito bem o efeito dessa modalidade de ensino que tem como diretriz filosófica o desenvolvimento do conhecimento a partir do âmbito em que o aprendiz está inserido envolvendo todas as diversificações, possibilitando a plena formação em consonância aos interesses e necessidades culturais.

Assim, emerge o desafio docente de operar múltiplos papéis e mediar o conhecimento em um contexto em que os alunos estão dispersos geograficamente (CARVALHO, 2007). Para tanto, faz-se necessário adotar estratégias de ensino e mediação acadêmica na EaD por meio das TICs - Tecnologia de Informação e Comunicação.

A EaD permite que o aluno administre seu tempo e espaço de forma autônoma, porém exige que o docente adote práticas pedagógicas que auxilie o aluno a aprender a aprender de forma independente e proativa.

Para Moore (2007), a aprendizagem na educação a distância acontece com base na Teoria da Distância Transacional, que se fundamenta nos elementos: desenvolvimento da autonomia do aprendiz, o diálogo entre os alunos e a preocupação com a escolha de uma estrutura que possibilite este tipo de vivência. A EaD não é apenas separação entre alunos e professores, é um conceito pedagógico que descreve o universo de relações professor-aluno separados no espaço e no tempo. A separação entre alunos e professores afeta tanto o ensino quanto a aprendizagem, pois com a separação surge um espaço psicológico e comunicacional a ser transposto, denominado de distância transacional, ou seja, espaço onde ocorrem transações entre professor e aluno.

Um fato de grande relevância nesse contexto educacional é a solidão que acomete o aluno ao estudar sozinho sem um contato com outras pessoas. Para minimizar esse problema é necessário a aplicação de métodos integrativos, dentre eles encontros presenciais para proporcionar uma relação afetiva e construtiva.

Os novos elementos tecnológicos vêm possibilitando uma nova razão cognitiva, novos caminhos para construir o conhecimento, reorganizar a visão de mundo de seus usuários e modificar seus reflexos mentais, aparecendo novas habilidades cognitivas (COELHO e MIRANDA, 2012). 
A tecnologia educacional tem avançado da abordagem condutivista para a educação cognitiva, passando a considerar os fatores sociais, culturais e institucionais que afetam o indivíduo. É preciso contextualizar e considerar o impacto nos indivíduos, na sociedade e no ambiente, estimulando nos estudantes o interesse pela aprendizagem através da disponibilidade ampla de novos conhecimentos e técnicas mediáticas. No contexto da educação a distância, o professor encontra-se mais distante da transmissão de conteúdos previamente planejados; exige-se dele o papel de arquiteto do conhecimento (Silva, 2003).

\section{Métodos Aplicados nos Encontros Presenciais}

Os cursos técnicos ofertados pelo Senai Goiás possuem uma carga horária de $80 \%$ (oitenta por cento) a distância e $20 \%$ (vinte por cento) presencial, em conformidade com a legislação brasileira vigente. A abordagem dos conteúdos e atividades realizadas a distância ocorre por meio do Ambiente Virtual de Aprendizagem (AVA), onde o aluno tem acesso aos materiais em formato PDF, scorm (conteúdo online), livro digital, vídeos e periódicos. Durante todo o curso, que tem duração em média de 18 (dezoito) meses, ocorre a mediação por parte do tutor que possui responsabilidades inerentes a formação de profissionais críticos e analíticos nas áreas de conhecimento. Dentre essas responsabilidades podemos citar: mediação afetiva com foco no pertencimento, aplicabilidade de ações dinamizadas por meio das ferramentas disponíveis, acompanhamento diário incluindo o esclarecimento de dúvidas e orientação das dificuldades, comunicação robusta com mensagens semanais acompanhadas de dicas e conteúdos complementares, dentre outras.

O aluno que estuda a distância desenvolve uma nova maneira de aprendizado por meio da interatividade, com isso ele passa a vivenciar sua autonomia e entender sua responsabilidade no processo. Daí a importância do tutor em motivar os alunos com diferentes conhecimentos, despertando nos educandos o rompimento da cultura do ensino presencial. Hurd (2005) discute a capacidade de reflexão dos educandos como fundamentos essenciais no processo de exercer a autonomia. Quando o tutor, por meio de retroalimentação consegue que o educando comece a se autogerir, dá-Ihe a certeza da capacidade de se habilitarem nos atos de aprendizagem.

Para desenvolver a aprendizagem significativa os encontros presenciais dos cursos técnicos do Senai-GO são previamente planejados pela equipe multidisciplinar, considerando os fatores sociais, culturais e institucionais. Coordenadores e tutores estruturam os planos que contemplam a aplicabilidade de Situações de Aprendizagem (SAP) contextualizadas de acordo com a prática profissional e a realidade de mercado. 
É uma ação pedagógica que avança para além do mero conhecimento ou do simples desempenho expresso em uma atividade prescrita, pois estimula o desenvolvimento de capacidades que permeiam transversalmente as competências. $O$ objetivo do docente é transcender a reprodução de conteúdo e a automatização de técnicas de forma a favorecer o desenvolvimento de capacidades que permitam ao aluno planejar, tomar decisões e realizar com autonomia determinadas atividades ou funções, transferindo tais capacidades desenvolvidas para diferentes contextos.

As situações de aprendizagem fazem parte da metodologia SENAI de Educação Profissional que tem um fluxo de definição de itinerário, construção de planos de curso que orienta 0 desenvolvimento de capacidades técnicas essenciais a formação profissional do aluno com base em competências, habilidades e atitudes. Nesse modelo de mediação pedagógica a avaliação dessa prática não se traduz em uma nota específica, mas na capacidade de planejar, compreender e demonstrar o conhecimento adquirido, promovendo a autonomia, criatividade e iniciativa.

O docente deve mobilizar a criatividade dos alunos estimulando o livre pensar, 0 interesse pelo novo, o pensamento divergente, a aceitação da dúvida como propulsora do pensar, a imaginação e o pensamento prospectivo com o objetivo de lançar o olhar para a inovação. Ao incentivar o pensamento criativo, o docente oportuniza aprendizagens que vão além da mera reprodução da realidade, propiciando a descoberta de novas perspectivas e de soluções ainda não pensadas. Para Morin (1999), o termo educação é considerada a utilização de meios que permitem assegurar a formação e o desenvolvimento do ser humano, capacitando-o a pensar e intervir na realidade. Pressupõe aptidões cognitivas e atitudes para a convivência em sociedade, e a construção de sentido para o mundo se torna o foco principal de um processo educativo.

As atividades aplicadas aos alunos no momento presencial contemplam estudo de caso, situação-problema, pesquisa aplicada, debates, simulação e prospecção e desenvolvimento de projetos, assim tudo que foi estudado na teoria apresentada no ambiente virtual de aprendizagem é convertido em aplicabilidade prática. Durante 0 desenvolvimento dessa atividade, o professor responsável analisa o desempenho dos alunos por meio da avaliação formativa e somativa, identificando o grau de dificuldade, estimulando o trabalho em equipe e despertando o lado crítico como profissional.

\section{Considerações Finais}

A estratégia de aprendizagem desafiadora, no âmbito da educação profissional, deve 
ser planejada tendo em vista o "aprender a fazer fazendo", ou seja, deve criar espaços que oportunizem, ao aluno, vivenciar práticas profissionais atinentes à ocupação. O planejamento da estratégia de aprendizagem desafiadora exige do docente competência para reunir conteúdos formativos das unidades curriculares, considerando o grau de sua complexidade e a dificuldade possível para os alunos num determinado momento, a fim de encontrar a dimensão ideal do desafio.

Atividades com essa estrutura possuem utilidade e significado para o trabalho e para a vida, sendo tal aproximação facilitadora da inserção profissional e da manutenção do trabalhador em atividade produtiva, pois favorece a compreensão das diferentes culturas do mundo do trabalho. Implica em garantir a complementaridade que se estabelece entre essas duas dimensões, possibilitando ao aluno aplicar os fundamentos e capacidades em sua prática profissional diária. A integração entre teoria e prática habilitará o aluno a avaliar e explicitar caminhos e alternativas na resolução de problemas, além de possibilitar a transferência das aprendizagens no enfrentamento de situações inusitadas e mais complexas.

Nesse sentido, os encontros presenciais devem propiciar a oportunidade do aprender fazendo, de modo a mobilizar o aluno afetiva e cognitivamente para que ele reconheça o real significado daquilo que está sendo aprendido. Implica prover e resguardar os espaços de acolhimento, da boa convivência, da empatia, do bem-estar, da solidariedade, da alegria e do otimismo no ambiente escolar, sem comprometer a seriedade e a atenção que os processos de ensino e aprendizagem exigem. Em essência, preserva-se o papel fundamental da educação: apoiar a realização de cada um e de todos no processo de desenvolvimento das competências.

Para tanto, deve-se despertar no aluno a motivação para aprender, o interesse por querer saber mais e melhor, pois ao favorecer o autodidatismo a metodologia mobiliza no aluno a capacidade e a iniciativa de buscar por si mesmo novos conhecimentos, favorecendo a curiosidade, a autonomia intelectual e a liberdade de expressão. No momento atual, em que o conhecimento que se aplica hoje pode não mais se aplicar amanhã, mobilizar o aprender a aprender é fundamental para favorecer ao educando descobrir suas próprias ferramentas para enfrentar as mudanças constantes e os desafios que elas acarretam.

\section{Referências}

CARVALHO, Ana Beatriz. Os múltiplos papéis do professor em educação a distância: uma abordagem centrada na aprendizagem. In: $18^{\circ}$ Encontro de Pesquisa 
Educacional do Norte e Nordeste. EPENN. Maceió, 2007.

COELHO, Maria de Lourdes. A evasão nos cursos de formação continuada de professores universitários na modalidade de educação a distância via internet. Artigo. ABED, 2001.

HURD, S. Autonomy and the distance language learner. In: Holmberg, Boerje; Shelley, Monica and White, Cynthia eds. Distance education and languages: evolution and change. New perspectives on language and education. Clevedon, UK: Multilingual Matters, pp. 1-19. Disponível em: Acessoem: 26 jun. 2018.

MOORE, R. Educação a distância. Uma visão integrada. Thompsom Pioneira: 2007.

MORAN, J. M. A educação que desejamos: novos desafios e como chegar lá. Gampinas, SP: Papirus, 2007.

MORIN, E. Os sete saberes necessários à educação do futuro. São Paulo: Cortez, 1999.

SENAI. Departamento Nacional. Metodologia Senai de Educação Profissional. Brasília: Senai DN, 2013.

SIMÕES, A. Incentivar Métodos de Estudo. Disponívelem. Acesso em: 20 jun. 2018. 